\title{
Two cases of acute torsion of the gall bladder
}

\author{
MONORANJAN DUARI
}

From the General Hospital, Burnley, Lancashire

EDITORIAL SYNOPSIS Two cases of torsion of the gall bladder, both associated with lax mesenteries, one with and one without a stone, are reported. It is remarkable that two such rare cases should be admitted under the care of one surgeon within two years.

CASE 1

H.P.S., a man aged 86 years, reported to his own doctor on the night of 23 May 1963 because of upper and rightsided abdominal pain and intermittent vomiting for 24 hours. His own doctor did not find anything of note on examination then. He revisited the patient on the morning of 24 May because of persistent symptoms. To quote his findings on this examination: 'Temperature normal: pulse 86 per min.: abdomen too hard to feel anything abnormal but he is definitely tender when I press to the right of mid-abdomen at the level of the umbilicus. I could not pick up any bowel sounds.' On the patient's admission to the hospital at mid-day on 24 May further questioning did not reveal any history of dyspepsia or jaundice. He had no urinary disturbance but the bowels had been constipated since the illness started.

A right femoral hernia had been repaired in 1951, and he had had attacks of bronchitis.

The patient was a slightly built, slightly dehydrated man; temperature $97^{\circ} \mathrm{F}$., pulse 102 per min., regular; blood pressure $120 / 70 \mathrm{~mm}$.Hg. No icterus.

No murmur or irregular beats were heard but there were a few scattered rhonchi in the lungs. The abdomen was rigid all over, and a mass was felt in the right lumbar and iliac region. Few bowel sounds were heard. The renal angles were not tender.

Rectal examination showed no mass, blood, or mucus on the finger. There might have been an area of tenderness over the peritoneal pouch. The condition was first diagnosed as perforated appendicitis, but later the diagnosis was changed to acute cholecystitis (? perforated) or perforated peptic ulcer.

Operative findings at laparotomy (right upper paramedian) were thin sanguinous, mostly subhepatic, free peritoneal fluid. The gall bladder was hugely distended, dark, and twisted clock-wise one and a half times on its mesentery. After untwisting, it was found to have a mesentery clothing nearly the whole organ and measuring nearly 2 in. in width (from the under surface of the liver to the gall bladder). There was a large (nearly 3 in. in its greatest diameter) solitary stone inside the gall bladder. Its dry weight was $28 \mathrm{~g}$. (1 oz.) and possibly it is one of the heaviest stones recorded. Meckel's celebrated gall stone weighed 30-36 g. (Rains, 1964).
The cystic duct as well as the common bile duct did not show any sign of inflammation.

An easy cholecystectomy was performed, and the abdomen closed in layers with a drain in the right subhepatic space. On opening the gall bladder it showed haemorrhagic fluid inside it as well as the stone.

Histologically the gall bladder was seen to be infarcted and contained many areas of haemorrhage without any inflammatory changes.

The patient's post-operative recovery was uneventful and he was very well a year later.

\section{CASE 2}

Mrs. M.H., aged 73 years, was admitted to Reedyford Memorial Hospital on 21 August 1964, because of upper abdominal pain of nearly 36 hours' duration.

She was well until 19 August when she developed a painful swelling in the right groin. She vomited once. Her own doctor visited her on 20 August and reduced the swelling, but afterwards the patient's pain increased in severity and became generalized. Although nauseated she did not vomit again. Appetite was poor. The bowel moved once, on 20 August, and on admission she was passing abundant flatus. She had no fever and no urinary complaints, but felt short of breath.

The patient had had recurrent attacks of bronchial asthma and bronchitis for the past 12 years. A pelvic floor repair was done seven years previously. Fifteen months ago she attended the Surgical Out-patient Clinic because of a slowly enlarging lump on the left side of the abdomen. This was painless and seemed to vary in size with a tendency to become larger after heavy work. Clinical examination, however, revealed no intraabdominal mass and a barium enema showed a few diverticulae in the pelvic colon.

On examination, the patient was a frail, elderly, moderately dyspnoeic woman (temperature $97^{\circ} \mathrm{F}$., pulse 128 per min. regular, respiration, 28 per min., blood pressure $150 / 90 \mathrm{~mm} . \mathrm{Hg}$ ). No engorged neck veins or lymphadenopathy were seen.

The antero-posterior diameter of thechest was increased. Rhonchi were heard in both lungs, but no heart murmur was heard. In the abdomen there was no distension, and no masses were felt. Tenderness over the right lower quadrant was marked. An irreducible femoral hernia was 
felt. Bowel sounds were hypoactive. Rectal examination revealed no masses and no discharge, but tenderness on the right rectal wall. The abdominal condition was judged to be an irreducible femoral hernia: on examination one hour later the femoral hernia was reduced but there was marked tenderness with guarding both in the right iliac fossa and right hypochondrium. The differential diagnosis was then acute cholecystitis, acute appendicitis, or gall stone ileus. In view of the patient's poor general condition conservative management was advised.

The following investigations were done: haemoglobin, $69 \mathrm{~g}$./100 ml.; white blood cells, 12,600 per c.mm.; serum bilirubin, $1.2 \mathrm{mg} . \%$; thymol turbidity, 1 unit; alkaline phosphatase, 6.0 units; blood urea nitrogen, $51 \%$. A straight radiograph of the abdomen did not show any evidence of acute intestinal obstruction.

On the evening of 23 August a mass in the right hypochondrium was suspected and the diagnosis was changed to one of acute cholecystitis but as the patient

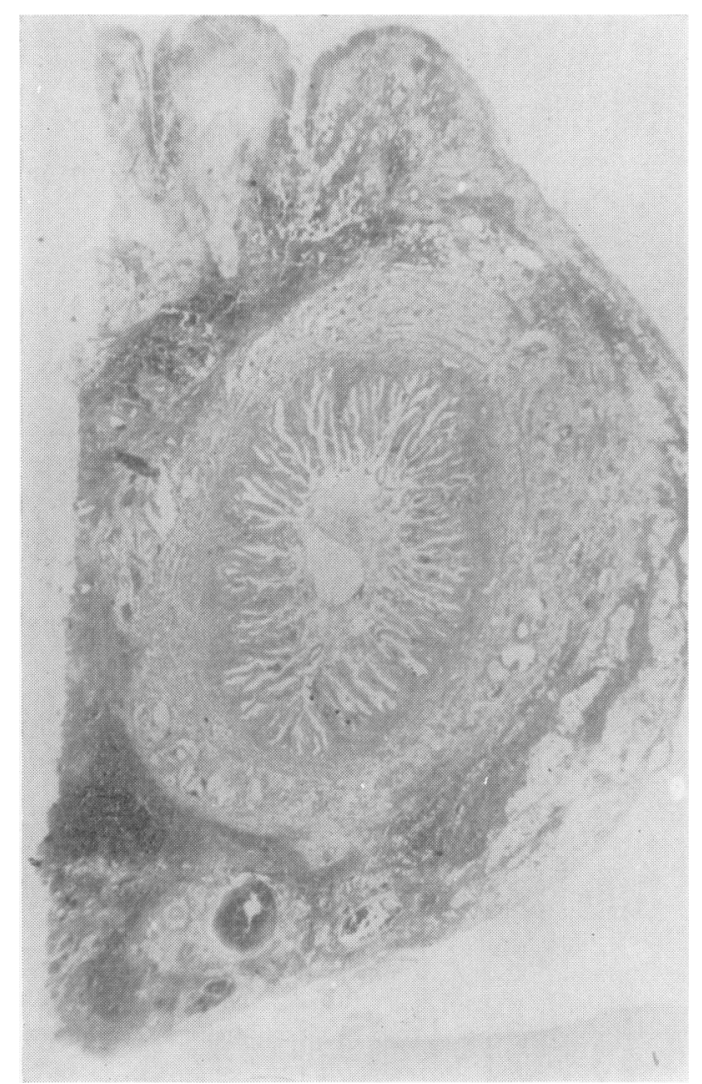

FIG. 1. Infarction of the wall of the gall bladder (dark areas in low power) with congestion of the vessels and haemorrhages into the stroma. Haemorrhages are mainly in the peripheral parts. The gall bladder also shows glandular hyperplasia. was feeling a little better operation was deferred. However, next morning, as there was no satisfactory progress, operation was decided upon.

Operative findings at laparotomy (right upper rectussplitting paramedian incision) were: dark brown free peritoneal fluid, mostly in the right paracolic gutter; a gangrenous, distended gall bladder, twisted anti-clockwise one and a half times at the cystic duct around a small mesentery near the duct. After untwisting, cholecystectomy was performed easily. The abdomen was closed in layers with a drain in the subhepatic space. The opened gall bladder contained no pus, no stone, but dark haemorrhagic fluid.

The histology of the infarcted wall of the gall bladder is illustrated in Figure 1.

Although the patient developed atelectasis in the postoperative period she ultimately recovered well and was found in satisfactory health six months later.

\section{DISCUSSION}

Wendel (1898) reported the first case of a floating gall bladder and kidney in a woman of 23 years. The gall bladder underwent torsion at the cystic duct which had a mesentery 2 in. long. Levene (1958) estimated 200 cases reported in the literature up to then. Since then further cases have been reported. That the condition is uncommon is proved by the fact that each of these authors who described one, two, or even three cases must have performed several hundred cholecystectomies. In discussing their experiences with 1,356 cases of cholecystitis and cholelithiasis at the Lahey Clinic, Colcock and McManus (1955) have not reported a single case of torsion in their operative findings. Having searched the records of some 250 cholecystectomies over a 10-year period (1954-63), I did not find another instance of torsion of the gall bladder. Nevertheless, as Haines and Kane (1948) have pointed out, the condition should be seen more often as there is a growing population of aged people.

The exact aetiology is unknown. Several factors have been discussed, and of these the most important single predisposing factor appears to be an anatomical abnormality in the attachment of the mesentery. Brewer (1899), from his findings after dissecting 100 cadavers, found a distinct mesentery in five cases. The gall bladder may hang from the liver when it is long or it may be free of mesentery except a small area near the neck and cystic duct. The disease is commoner among thin, elderly people, most cases occurring between the ages of 60 and 80 years, and $84 \%$ of them are in women (quoted by Rodney Maingot in Smith and Sherlock, 1964). Loss of fat, cirrhotic changes, kyphoscoliotic changes (Mouzas, 1960), arteriosclerotic changes in the cystic artery (Caldwell, 1950), all have been reported to be predisposing factors. Stones were not present in all 

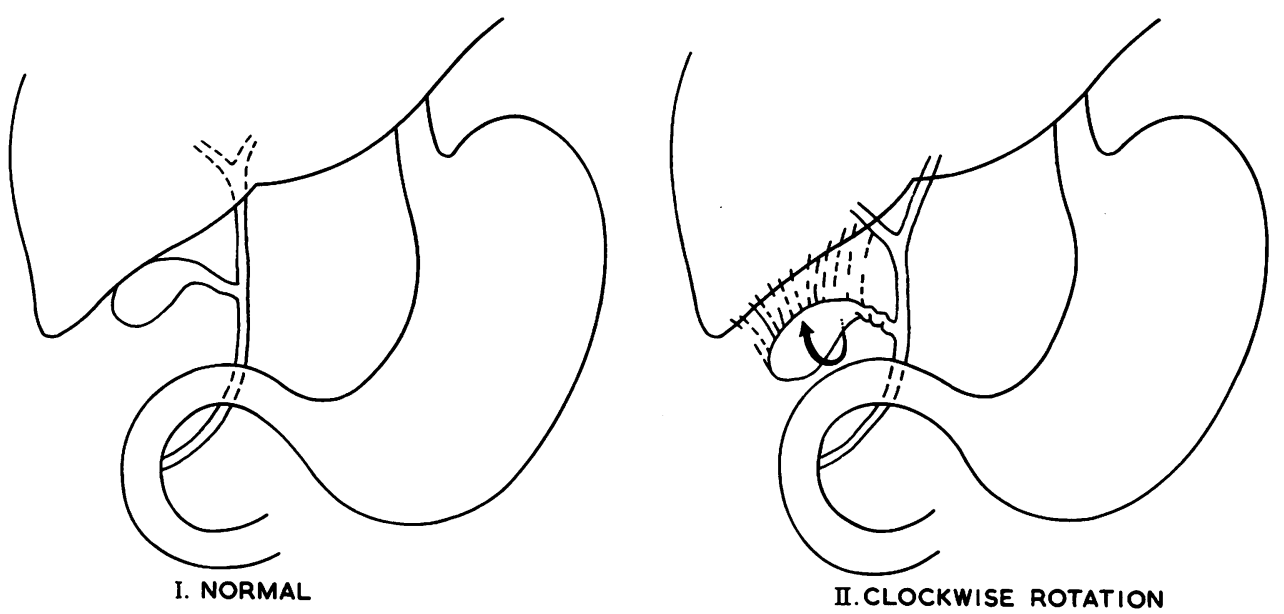

FIG. 2. The normal gall bladder and two common anatomically abnormal gall bladders. In II the gall bladder has a long wide mesentery and the male case quoted here conforms to this type; III shows a gall bladder where there is a very small mesentery attached only to the cystic duct and neck of the gall bladder. The woman quoted here conforms to this type.

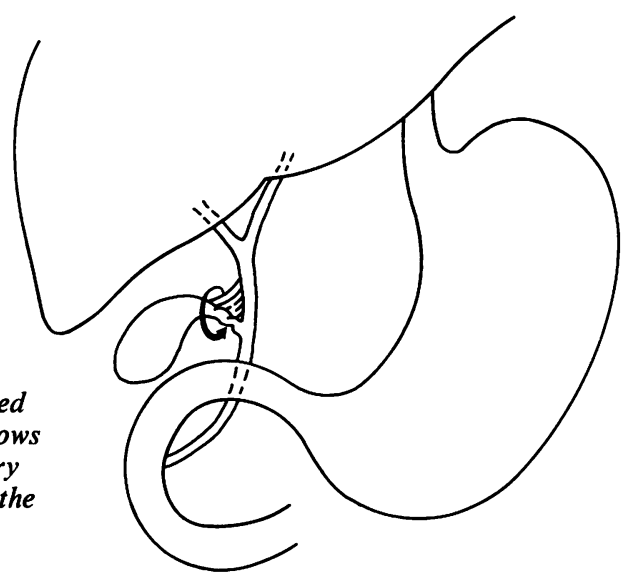

III. ANTICLOCKWISE ROTATION

the cases; in fact they were present in less than half the cases. But Levene (1958) has pointed out that a heavy organ is likely to tort and an increase in weight may be due to a large stone (as in case 1) or blockage of the cystic duct. From my experience of volvulus of the sigmoid colon in India, I believe that an analogous condition is quite possible in an anatomically abnormally heavy gall bladder. The actual initiating factor in torsion is also unknown. Gastric, duodenal, or colonic peristalsis has been held responsible by some authors (Barber, 1939; Skinner, 1953). Trauma or muscular action has been suggested as a more likely cause of torsion by displacing a mobile gall bladder (Shepherd, 1960). In the second case reported here the patient's own doctor attempted to reduce the right femoral swelling (?hernia) the night before the upper abdominal pain became more severe.

An accurate pre-operative diagnosis is unusual
(Carter, Thompson, Brennan, and Hinshaw, 1963). Few (Short and Paul, 1934; Rawson, 1953) have diagnosed correctly before operation, although the former authors were confident that a pre-operative diagnosis could often be made. I, however, agree that their (Short and Paul, 1934) remarks about the diagnostic criteria are commendable. They wrote: 'A pre-operative diagnosis could often be made, the grounds being the occurrence of pain, vomiting, especially in an elderly female with a palpable tumour having the characters of a gall bladder which comes up within a few hours and may appear and disappear.' To these may be added absent or mild pyrexia and absence of jaundice. The lump of course could be felt only in a third of the cases (Carter et al., 1963). The position of such a lump would be determined by the amount of mobility of the viscus and this may be at any point within the radius of its mesentery (Brewer, 1899). In retrospect, it appeared 
that the second patient in fact had a mobile lump with possible mild incomplete attacks of torsion.

However, the common conditions which were diagnosed pre-operatively were acute appendicitis, acute cholecystitis, and acute peptic ulcer perforation (Christensen, 1956). The two cases reported here conform to this pattern. In spite of dealing with the first case only fifteen months ago, I did not venture the diagnosis of torsion in the second case and operated because of unresolving acute cholecystitis.

Management of the condition is early surgery and cholecystectomy. Mortality in recent years is below $5 \%$ (Rodney Maingot in Smith and Sherlock, 1964). Nevertheless a high mortality and morbidity would be expected in cases where late management had been instituted.

\section{SUMMARY}

Two cases of acute torsion of the gall bladder in elderly people are reported; one of them may have had recurrent mild attacks in the past.

The aetiology is discussed, and the suggestion is made that an anatomically mobile heavy organ may be a possible factor in torsion. The male patient had one of the heaviest stones recorded. Early diagnosis and cholecystectomy will ensure safety in these elderly people.

My sincere thanks are due to Mr. A. H. Thomson, consultant general surgeon, General Hospital, Burnley, Lancashire, under whose care these cases were admitted and whose constant inspiration and help made this paper possible; to Dr. G. Behr, consultant pathologist of the above group, for photomicrographs and histological reports; to Mr. C. Shepley, of the Medical Illustration Department of the University of Edinburgh, for illustrations; and to Miss Wardle, the Librarian at the Royal College of Surgeons of Edinburgh, for her help in arranging the references.

\section{REFERENCES}

Barber, A. H. (1939). Acute torsion of the gall bladder, Brit. med. J., 2, $1272-1273$.

Brewer, G. E. (1899). Preliminary report on the surgical anatomy of the gall-bladder and ducts from an analysis of one hundred dissections. Ann. Surg., 29, 721-730.

Caldwell, K. P. S. (1950). Torsion of the gall bladder. Brit. med. J., 2 , 1425.

Carter, R., Thompson, R. J. Jr., Brennan, L. P., and Hinshaw, D. B. (1963). Volvulus of the gallbladder. Surg. Gynec. Obstet., 116, 105-108.

Christensen, E. (1956). Torsion of the gall bladder. Brit. med. J., 2, 1160.

Colcock, B. P., and McManus, J. E. (1935). Experiences with 1,356 cases of cholecystitis and cholelithiasis. Surg. Gynec. Obstet., $101,161$.

Haines, F. X., and Kane, J. T. (1948) Acute torsion of the gall bladder, Ann. Surg., 128, 253-256.

Levene, A. (1958). Acute torsion of the gall-bladder: post-mortem findings in two cases. Brit. J. Surg., 45, 338-340.

Maingot, R. (1964). Ptosis of the gall bladder. In Surgery of the Gall-bladder and Bile Ducts, edited by R. Smith and S. Sherlock, pp. 18-19. Butterworths, London.

Mouzas, G. L. (1960). Torsion of the gallbladder in a kypho-scoliotic patients Postgrad. med. J., 36, 686-697.

Rains, A. J. H. (1964). Gall-stones: Causes and Treatment, p. 14. Heinemann, London.

Rawson, H. D. (1953). Torsion of the gall-bladder in a child of 12 with a review of the literature. Aust. N.Z.J. Surg., 22, 315-317.

Shepherd, J. A. (1960). Surgery of the Acute Abdomen, p. 680. Livingstone, Edinburgh.

Short, A. R., and Paul, R. G. (1934). Torsion of the gall-bladder. Brit. J. Surg., 22, 301-309.

Skinner, E. W. O. (1953). Torsion of the gall-bladder. Brit. med. J., 2, 662.

Wendel, A. V. (1898). A case of floating gall-bladder and kidney complicated by cholelithiasis with perforation of the gallbladder. Ann. Surg., 27, 199-202. 